\title{
GENERAL ANAESTHESIA IN EIGHT PATIENTS WITH FAMILIAL DYSAUTONOMIA*
}

\author{
H. W. MERIDY, M.D., F.A.C.A. AND \\ R. E. CREIGHTON, M.D., F.R.C.P. (C) $\uparrow$
}

Familat dysautonomia, a rare syndrome typically involving Jewish children is probably transmitted as a simple autosomal recessive gene. ${ }^{1-4}$

During the past 15 years, eight patients with familial dysautonomia underwent a total of 24 surgical procedures under general anaesthesia at The Hospital for Sick Children, Toronto. The purpose of this paper is to review our experience with these eight patients with particular reference to anaesthetic management.

\section{Clinical Picture}

The clinical manifestations of familial dysautonomia result from autonomic, motor, sensory, and psychic disturbances. ${ }^{2}$ Those manifestations of special interest to the anaesthetist are listed in Table $\mathrm{I}$.

The condition may be recognized in the newborn infant by vasomotor episodes, pallor and unresponsiveness, failure to respond to pain, hypotonia, and inability to suckle and swallow. ${ }^{5}$ In the infant recurrent aspiration pneumonia, excessive drooling, difficulty swallowing, and the absence of overflow tears suggest the diagnosis. In older children, emotional lability, retarded growth, periodic vomiting, abdominal pain. and erratic temperature control may be the presenting symptoms. ${ }^{2}$

\section{Diagnosis}

The diagnosis of familial dysautonomia is established by history and physical examination. A smooth tongue with absent taste buds and filiform papillae is the simplest and most reliable sign of the disease, ${ }^{6.8}$ Postural hypotension is also important. 2

The diagnosis can be confirmed by several tests. Urinary homovanillic acid (HVA) excretion is elevated while vanillylmandelic acid (VMA) excretion is significantly depressed.9,10 The normal radiating pain and flare response to intradermal histamine (1:1000) is absent. ${ }^{11}$ A miotic response to the instillation of dilute ( 2.5 per cent) methacholine into the conjunctival sac, absence of tears, corneal hypaesthesia, and exodeviation make up an opththalmologic tetrad seen in dysautonomia. ${ }^{12,13}$

The basic defect in dysautonomia is unknown. Motor, sensory, and psychic dis-

${ }^{*}$ From the Department of Anaesthesia, University of Toronto and The Hospital for Sick Children, Toronto 101, Ontario, Canada.

Presented at the Annual Meeting, Canadian Anaesthesists' Society, June 29, 1971.

†Address for Reprints: Dr. R. E. Creighton, Department of Anaesthesia, The Hospital for Sick Children, 555 University Avenue, Toronto 101, Ontario, Canada.

Canad. Anaesth. Soc. J., vol. 18, no. 5, September 1971 


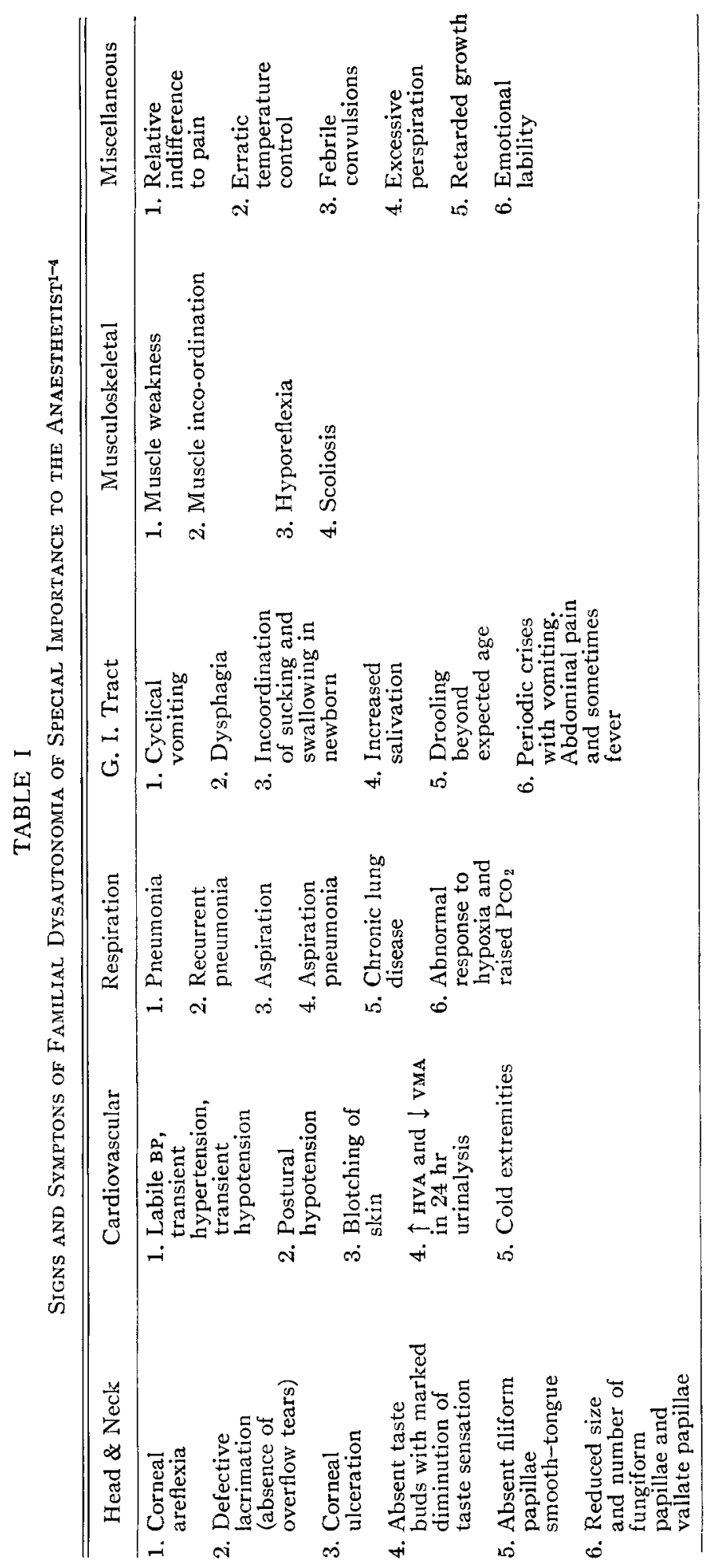


turbances in addition to autonomic dysfunction suggest diffuse involvement of the entire nervous system. ${ }^{2}$

Many of the features of dysautonomia may be due to deficient sensory perception. ${ }^{13,14}$ The dysautonomic may suffer considerable trauma with a minimum of pain. Loss of taste discrimination is associated with absent taste buds. ${ }^{6,15,16}$ When the ambient concentration of $\mathrm{CO}_{2}$ is increased the compensatory increase in ventilation is less than in normal persons, ${ }^{17}$ perhaps due to deficient chemoreceptors. The characteristic postural hypotension may be due to deficient baroreceptors. Finally, motor incoordination may result from deficient kinaesthesia rather than neuromuscular deficiency.

Alfred A. Smith and Joseph Dancis, in a series of experiments, examined the autonomic derangement in familial dysautonomia. They suggested that many features of familial dysautonomia could be due to insufficient acetylcholine, the chemical transmitter in all preganglionic and postganglionic parasympathetic fibres. ${ }^{13}$ The dose of infused methacholine chloride (stimulant to parasympathetic postganglionic fibres and salivary and sweat glands) necessary to produce parasympathetic symptoms is less for dysautonomics than for normal persons. ${ }^{18}$ Certain functions such as patellar jerks, histamine flare, and overflow tears, regularly deficient in dysautonomics, were restored during intravenous methacholine infusions. The return of taste discrimination has also been reported. ${ }^{16}$

Since acetylcholine is also the neurotransmitter of the sympathetic ganglia ${ }^{19}$ and the postganglionic cholinergic sympathetic fibres responsible for vasodilatation and perspiration, the response to infused norepinephrine was examined. ${ }^{20}$

The dysautonomic displays an exaggerated hypertensive response to norepinephrine without the normal coincident bradycardia which is mediated through the parasympathetic system. Therefore, parasympathetic deficiency may have contributed to the exaggerated response. Blotching of the skin identical to that which occurs spontaneously in dysautonomics was also observed during norepinephrine infusion. Since an insufficiency of a neurotransmitter is followed by an increased sensitivity to the same agent, it was suggested that these symptoms of the disease could represent an exaggerated response to endogenous norepinephrine.

Catecholamine metabolism in dysautonomics was therefore studied ${ }^{9}$ and demonstrated a high homovanillic acid (HYA) and low vanillylmandelic acid (MMA) urinary excretion rate. Vanillylmandelic acid originates from the degradation of epinephrine and norepinephrine while homovanillic acid originates from their precursors suggesting that the dysautonomic suffers from an insufficiency of catecholamines with a shunting of precursors to homovanillic acid.

Since the dysautonomic's exaggerated responses to infused norepinephrine ceased promptly when the infusion was stopped, it was concluded that the deficiency was due to inadequate release of the catecholamine rather than insufficient synthesis or degradation. ${ }^{21}$

\section{ANAESTHETIC EXPERIENCE}

Kritchman, Swartz, and Papper (1959) reported on 26 general anaesthetics in eight patients with dysautonomia. ${ }^{22}$ McCaughey in 1965 reported on six general 
anaesthetics in one patient, ${ }^{23}$ and Bartels and Mazzia (1970) reported two general anaesthetics in a single patient. ${ }^{24}$

The 24 operative procedures carried out on our eight patients are listed in Table II. The youngest patient was three months old, and the oldest 18 years. The shortest procedure was 20 minutes and the longest 4 hours and 40 minutes.

TABLE II

Operative Procedures

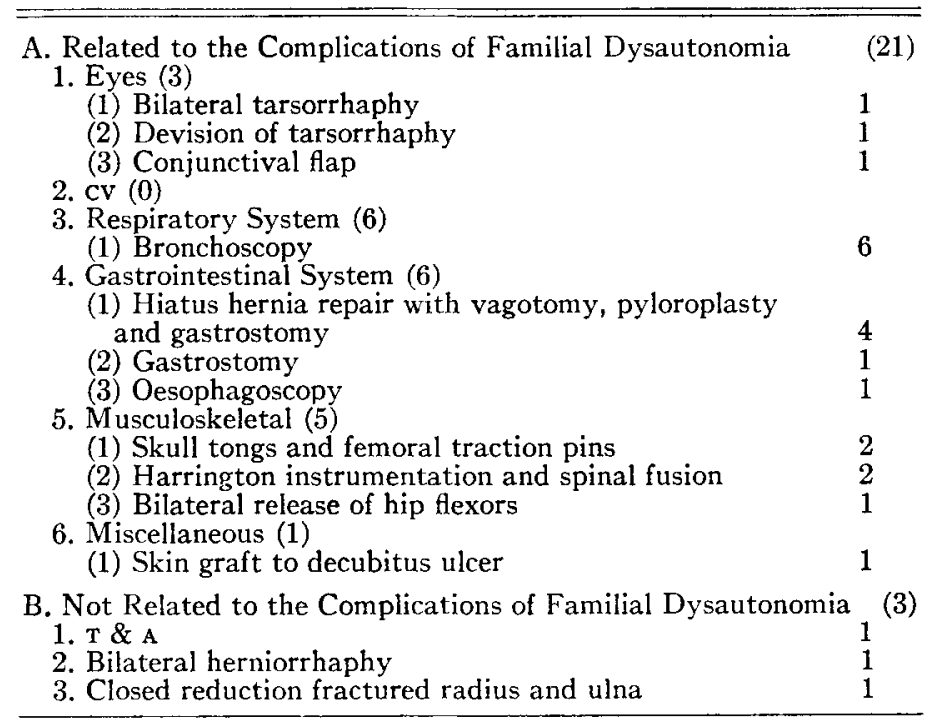

\section{Preoperative Management}

Functional defects in the respiratory system of patients with dysautonomia present the most serious preoperative problems. Recurrent pneumonia leads to chronic lung disease. Incoordination of sucking and swallowing in the newborn and dysphagia in the young child allow repeated aspiration leading to pneumonia and chronic pulmonary disease. A raised serum antibody titre against milk can be demonstrated in these patients. ${ }^{25}$ Thick bronchial secretions, resulting from inadequate parasympathetic activity, may contribute to pulmonary disease. ${ }^{28}$

Chlorpromazine and atropine have been recommended as preanaesthetic medications. ${ }^{22,23}$ The use of chlorpromazine as an emotional stabilizer and as a prophylactic against vomiting is questionable in a patient with a labile cardiovascular system because of its adrenergic blocking effect. In our series four patients on maintenance chlorpromazine and two others who received chlorpromazine premedication suffered no severe hypotensive episodes during induction of anaesthesia.

Belladonna drugs tend to thicken bronchial secretions. Before induction patients received intramuscular atropine in nine instances and intravenous atropine in ten. Since the majority of these patients had chronic respiratory problems the effect on secretions could not be assessed. Although an inadequate sympathetic nervous 
system has been postulated in dysautonomia, most of the patients receiving atropine had a normal tachycardia response.

The heart rate was only 85 in a 5 -year-old girl weighing $14.5 \mathrm{~kg}$ five minutes after giving $0.3 \mathrm{mg}$ of atropine intravenously during induction. During the operation under nitrous oxide-oxygen-curare anaesthesia, atropine $0.1 \mathrm{mg}$ intravenously given on two occasions produced no change in a heart rate of 95 beats per minute. However, prior to prostigmine reversal, $0.3 \mathrm{mg}$ of atropine intravenously produced an increase in heart rate from 120 beats/minute to 140 beats/minute.

\section{Intraoperative Management}

The most serious intraoperative problems are labile blood pressure with transient hypertension and hypotension, postural hypotension, blotching of the skin, and cold extremities.

Lesser problems are corneal areflexia, defective lacrimation, muscle weakness and restrictive pulmonary disease associated with scoliosis. Insensitivity to pain may be an advantage in the intraoperative period but a disadvantage postoperatively if pressure ulcers develop.

Induction with intravenous agent was used in 12 anaesthetics after atropine premedication. Thiopentone sodium was used in nine. One $15 \mathrm{~kg}$ child received 10 $\mathrm{mg} / \mathrm{kg}$ and one $18 \mathrm{~kg}$ child received $3.3 \mathrm{mg} / \mathrm{kg}$. The remaining patients received normal paedriatric doses, 4.2 to $5.6 \mathrm{mg} / \mathrm{kg}$. Methohexitone sodium $\uparrow$ was used in three anaesthetics, 1.8 to $2.3 \mathrm{mg} / \mathrm{kg}$. Neither agent produced the severe hypotension reported by other observers. ${ }^{22}$

Induction with inhalation agent was used in 12 anaesthetics with atropine premedication in seven. Nitrous oxide and halothane were used in five anaesthetics, ethyl chloride in four, ether in two and nitrous oxide alone in one. There were no episodes of severe hypotension. Halothane and methoxyflurane, especially in concentrations greater than 0.5 per cent, frequently produced cardiovascular depression; hence wide swings in blood pressure were recorded in some patients until the correct concentration for that child could be ascertained.

Ten patients responded normally to intravenous succinylcholine chloride + used to facilitate intubation. In spite of the abnormalities of acetylcholine action postulated in dysautonomia, response to succinylcholine was entirely normal.

Anaesthesia was maintained by a variety of techniques and agents. In twelve instances the anaesthetic was administered with an Ayre's T-piece. Respirations were spontaneous in six of these, controlled with a positive and negative phase ventilation in four, and controlled by hand in two. Six further anaesthetics were maintained with spontaneous respiration through a bronchoscope, four more with a non-breathing system, and the remaining two with ether and oxygen delivered by an ether hook.

Although decreased sensitivity to $\mathrm{CO}_{2}$ retention and hypoxia has been demonstrated in dysautonomia ${ }^{17}$ there was no evidence of this defect during 18 anaesthetics during which the patient breathed spontaneously (Table III).

- Pentothal Sodium(1. Abbott Laboratories Ltd., Montreal 9, Quebec.

†Brietal Sodium $\otimes^{8}$. Eli Lilly \& Co. (Canada) Ltd., Toronto 1, Ontario.

$\$$ Scoline ${ }^{\circledR}$. Glaxo-Allenburys (Canada) Ltd., Weston, Ontario. 
The absence of a normal protective catecholamine response to diethyl ether has been reported in dysautonomia. ${ }^{23}$ Our six anaesthetics using this agent were too short (20-25 minutes) to justify comment on this observation.

Adequate anaesthesia was obtained in five instances where $\mathrm{N}_{2} \mathrm{O}$ and halothane 0.5 per cent or methoxyflurane 0.5 per cent or both were used. Concentrations above this level depressed systolic blood pressure, as did lower concentrations in some instances. Nitrous oxide as the sole anaesthetic agent was adequate for two procedures.

TABLE III

Agents for Maintenance

\begin{tabular}{lcc}
\hline \hline \multicolumn{1}{c}{ Agent(s) } & $\begin{array}{c}\text { Number of } \\
\text { anaesthetics }\end{array}$ & $\begin{array}{c}\text { Duration } \\
\text { (minutes) }\end{array}$ \\
\hline A. Spontaneous Ventilation & & \\
1. Diethyl ether & 6 & $20-35$ \\
2. Nitrous oxide and halothane & 5 & $15-95$ \\
3. Nitrous oxide, halothane and methoxyflurane & 4 & $20-85$ \\
4. Nitrous oxide & 2 & $50-60$ \\
5. Diethyl ether and halothane & 1 & 60 \\
B. Controlled Ventilation & 3 & $140-280$ \\
1. Nitrous oxide-d-tubocurarine & 2 & $175-180$ \\
2. Nitrous oxide/methoxyflurane/d-tubocurarine & 2 & 220 \\
3. Nitrous oxide/halothane/d-tubocurarine & 1 & \\
\hline
\end{tabular}

TABLE IV

Curare Requirements for Controlled Ventilation

\begin{tabular}{lcc} 
Agents & $\begin{array}{c}\text { Duration } \\
\text { of Surgery }\end{array}$ & $\begin{array}{c}\text { Dose in mg/kg } \\
\text { per 45 min period }\end{array}$ \\
\hline 1. Nitrous oxide/d-tubocurarine & 140 & 0.51 \\
2. Nitrous oxide/d-tubocurarine & 205 & 0.4 \\
3. Nitrous oxide/d-tubocurarine & 280 & 0.4 \\
4. Nitrous oxide/halothane/d-tubocurarine & 220 & 0.3 \\
5. Nitrous oxide/methoxyflurane/d-tubocurarine & 175 & 0.2 \\
6. Nitrous oxide/methoxyflurane/d-tubocurarine & 180 & 0.25 \\
\hline
\end{tabular}

The action of d-tubocurarine in dysautonomics was investigated. Curare was given, with nerve stimulator control.

Curare requirements were within normal limits for normal patients at our hospital. No problem of residual curarization or recurarization was encountered.

\section{Postoperative Management}

The most serious problems occurred in the postoperative period. They included fever, residual lung infection, pulmonary obstruction by secretions, cardiovascular instability with hypertension and hypotension, nausea, vomiting and aspiration pneumonitis.

One 5-year-old with persistent lung disease developed secretional obstruction and respiratory failure following bronchoscopy and required nasotracheal intubation and artificial ventilation for 24 hours. 
An 18-year-old on maintenance chlorpromazine had a severe hypotensive episode after a $20 \mathrm{mg}$ dose of the drug eight days after operation. One month later he underwent a Harrington instrumentation and spinal fusion under general anaesthesia and 24 hours after operation had a severe hypotensive episode with respiratory arrest which responded to ventilation with oxygen. Several apnoeic spells during the next 12 hours necessitated intubation and controlled ventilation. Further complications included aspiration pneumonitis, left lower lobe pneumonia and left pleural effusion before final recovery.

One 16-year-old developed a decubitus ulcer on the buttock following bilateral hip-flexor release. This lesion, which required treatment by split-thickness skin graft, may have been due to decreased sensitivity to pain.

\section{SUMMARY}

Familial dysautonomia is a rare inherited disease. Its clinical manifestations result from autonomic, motor, sensory, and psychic disturbances and may present a difficult challenge to the anaesthetist. During the past 15 years, eight patients with familial dysautonomia have received 24 general anaesthetics at The Hospital for Sick Children, Toronto.

No single basic lesion has been isolated. There is clear evidence of a peripheral sensory defect. The autonomic disturbances may be related to deficient acetylcholine activity and a resultant insufficiency of catecholamines.

Preoperative residual chest infections, intraoperative cardiovascular instability, and postoperative vomiting and aspiration are the most frequent anaesthetic problems. The miscellaneous disturbances in dysautonomia, such as erratic temperature control, emotional lability, and retarded growth add to the difficulties in anaesthetic management.

Our experience with eight patients suggests that familial dysautonomia is not a contraindication to general anaesthesia. Premedication with chlorpromazine may be given where indicated and a normal response to atropine may be anticipated in most instances. If induction is performed carefully, both intravenous and inhalation techniques are reasonably safe. No evidence of decreased sensitivity to $\mathrm{CO}_{2}$ or hypoxia was demonstrated during anaesthesia. The response to d-tubercurarine appears normal. Because cardiovascular sensitivity to halothane and methoxyflurane may be encountered during maintenance anaesthesia, a combination of nitrous oxide, oxygen, curare and controlled ventilation is the best anaesthetic technique for these patients.

\section{RÉSUMÉ}

La dysautonomie familiale est une maladie héréditaire rare. Ses manifestations cliniques résultent de troubles autonomes, moteurs, sensitifs, et psychiques et elles peuvent présenter un défi difficile pour l'anesthésiste. Durant les 15 dernières années, huit malades souffrant de dysautonomie familiale ont reçu 24 anesthésies générales au "Hospital for Sick Children" de Toronto.

\footnotetext{
${ }^{\circ}$ Largactil $\$$. Poulenc Limited, Montreal 11, Quebec.
} 
Des infections pulmonaires résiduelles pré-opératoires, une instabilité cardiovasculaire per-opératoire et des vomissements et aspirations post-opératoires ont constitué les problèmes anesthésiques les plus fréquents. Notre expérience avec ces huit malades laisse entendre que la dysautonomie familiale n'est pas une contrindication à l’anesthésie générale.

\section{REFERENCES}

1. Riley, C. M.; Day, R. L.; Greeley, D. M. \& Langford, W. S. Central Autonomic Dysfunction with Defective Lacrimation. x. Report of Five Cases. Pediatrics, 3: 468 (1949).

2. RiLey, C. C. Familial Dysautonomia. Advances Pediat., 9: 157 (1957).

3. Hutchinson, J. H. \& Hamilton, W. Familial Dysautonomia in Two Siblings. Lancet, 1 : 1216 (1962).

4. Fellner, M. J. Manifestations of Familial Autonomic Dysautonomia. Report of a Case, with an Analysis of 125 Cases in the Literature. Arch. Derm. (Chicago), 89: 190 (1964).

5. Geltzer, A. I.; Gluck, L.; Talner, N. S. \& Poleskr, H. F. Familial Dysautonomia. Studies in a Newborn Infant. New. Eng. J. Med., 271: 436 (1964).

6. Smith, A. A.; Farbman, A. \& Dancis, J. Absence of Taste-Bud Papillae in Familial Dysautonomia. Science, 147: 1040 (1965).

7. Pearson, J.; Finegold, M. J. \& Budzilovich, G. The Tongue and Taste in Familial Dysautonomia. Pediatrics, 45: 739 (1970).

8. Moses, S. W.; Rotem, Y.; Jagoda, N.; Talmos, N.; Eichhorn, F. \& Levin, S. A Clinical, Genetic and Biochemical Study of Familial Dysautonomia in Israel. Israel J. Med. Sci., 3: 358 ( 1967).

9. SMith, A. A.; Taylor, T. \& Wortis, S. B. Abnormal Catechol Amine Metabolism in Familial Dysautonomia. New Eng. J. Med., 268: 705 (1963).

10. Grruow, S. E.; Bertani, L. M.; Wirk, E.; Lr, B. L. \& Dzifdzic, S. Excretion of Catecholamine Metabolites by Children with Familial Dysautonomia. Pediatrics, 46: 513 (1970).

11. SMrTH, A. A. \& Dancis, J. Response to Intradermal Histamine in Familial Dysautonomia. A Diagnostic Test. J. Pediat., 63: 889 (1963).

12. Smith, A. A.; Dancis, J. \& Breinin, G. Ocular Responses to Autonomic Drugs in Familial Dysautonomia. Invest. Ophthal., 4: 358 (1965).

13. Dancrs, J. Altered Drug Response in Familial Dysautonomia. Ann. N.Y. Acad. Sci., 151: 876 (1968).

14. Dancis, J. \& Sirtre, A. A. Familial Dysautonomia. New Eng. J. Med., 274: 207 (1966).

15. Smith, A. A. \& Dancis, J. Taste Discrimination in Familial Dysautonomia. Pediatrics, 33: 441 (1964).

16. Henkin, R. I. \& Kopin, I. J. Abnormalities of Tastes and Smell Thresholds in Familial Dysautonomia: Improvement with Methacholine. Life Sci., 3: 1319 (1964).

17. Firler, J.; Smith, A. A.; Stone, S.; \& Dancis, J. Respiratory Control in Familial Dysautonomia. J. Pediat., 66: 509 (1965).

18. Smith, A. A.; Hirsch, J. I.; \& Dancis, J. Responses to Infused Methacholine in Familial Dysautonomia. Pediatrics, 36: 225 (1965).

19. Burn, J. H. \& Rand, M. J. Sympathetic Postganglionic Cholinergic Fibres. Brit. J. Pharmacol., I5: 56 (1960).

20. Smith, A. A. \& Dancis, J. Exaggerated Response to Infused Norepinephrine in Familial Dysautonomia. New Eng. J. Med., 270: 704 (1964).

21. Smrth, A. A. \& Dancis, J. Catecholamine Release in Familial Dysautonomia. New Eng. J. Med., 277: 61 (1967).

22. Kritchman, M. M.; Schwartz, H. \& Papper, E. M. Experiences with General Anesthesia in Patients with Familial Dysautonomia. J.A.M.A., 170: 529 (1959).

23. McCaughex, T. J. Familial Dysautonomia as an Anaesthetic Hazard. Canad. Anaesth. Soc. J., 12: 558 (1965).

24. Bartels, J. \& Mazzia, V. D. B. Familial Dysautonomia. J.A.M.A., 212: 318 (1970).

25. Drucker, M. M.; Russell, A.; Kletter, B.; Gery, I.; Freier, S. \& Moses, S. W. Milk Antibodies in Familial Dysautonomia. Pediatrics, 44: 265 (1969).

26. Moloshox, R. E. \& Moseley, J. E. Familial Dysautonomia: Pulmonary Manifestations. Pediatrics, 17: 327 (1956). 